\title{
Innovation Facilitated by Universities: Balancing Enterprise and Regional Demands
}

\author{
Qi Wang (iD, Ling-Na Zhang $(\mathbb{D}$, and Qi Lian $(\mathbb{D}$ \\ School of Management, Beijing Union University, Beijing 100101, China \\ Correspondence should be addressed to Ling-Na Zhang; lingna.zhang@buu.edu.cn
}

Received 24 November 2021; Accepted 20 January 2022; Published 7 March 2022

Academic Editor: Daqing Gong

Copyright (c) 2022 Qi Wang et al. This is an open access article distributed under the Creative Commons Attribution License, which permits unrestricted use, distribution, and reproduction in any medium, provided the original work is properly cited.

\begin{abstract}
Innovation constitutes an important output of education. With the differences in the two-dimensional cooperation between universities, the government, and enterprises in the mode featuring "triple helix" as a starting point, this article has compared the features of the influence of differences in the quality of higher education on enterprise and regional innovation by adopting the data of listed companies and provincial-level macro-statistical data from 2013 to 2020 to construct the count panel data model. The research has proved that the "inverted U" feature is presented between the range of quality among universities and the level of innovation output. However, the coefficient of the differences in quality between universities in relation to the optimal innovation output of enterprises is higher than that of regional innovation output. That is to say, differences are existent in the differences in the path of the influence of the differences in quality between universities with respect to entrepreneurship and national innovation. To some extent, this research result explains the reason why the country has cultivated a large number of talents but is still faced with the situation characterized by the lack of talents related to the so-called crucial technologies. Therefore, on the basis of guaranteeing the basic operation rules of higher education, it is necessary for the third-party institutions to provide differentiated higher education information for enterprises and countries (regions) to realize the unity of the classification of schools in education and the signal of market-element allocation. Moreover, university alliances should be established so that the innovation demands based on enterprises and regions can be met through the transmission of information between universities so as to prevent universities from becoming tools for helping enterprises maximize their profits or for the government to pursue educational achievements.
\end{abstract}

\section{Introduction}

Firstly, higher education plays a very important role in innovation. The 14th Five-Year Plan for Economic and Social Development (2021-2025) has proposed the target of "optimizing the distribution of regional higher education resources." However, is the process of concrete implementation likely to lead to issues such as whether there is an inconsistency between the target of enterprises' demand for talents and that of a country or region's demand for talents and whether there are differences between the country's demand for strategic talents and enterprises' demand for profit optimization? Regarding the supply side of talents, should institutions of higher learning pay more attention to the differentiated competition or advance side by side? These issues should be focused on by relevant departments in their implementation of the 14th Five-Year Plan. In fact, World Development Report in 2018 and World Innovation Index Report in 2018 emphasized the new changes in education policy: Various countries had begun to shift their attention from educational input to educational output. As for the question of how to transform the investment in education, a lot of qualified researchers and research-and-development expenditures into high-quality innovation output is an issue with research value. Meanwhile, higher education is one of the significant variables affecting the level of innovation output [1].

Secondly, previous studies have shown that in China, due to the competition and substitution effect between twodimensional cooperation and overall three-dimensional cooperation, universities, enterprises, and the government had missed the opportunity to conduct two-dimensional 
cooperation with one of the three sides in the process of carrying out their three-dimensional cooperation [2] ultimately limiting innovation. Therefore, it is necessary to study not only the differences in the ways that universities influence enterprise innovation at the micro level but also the ways in which universities influence national and regional innovation at the macro level.

Thirdly, relative to the traits of applied and basic innovation results, enterprises demand more applied and exclusive innovation results, while innovation related to national and regional strategies needs more basic and weak exclusive research to support. Judging from the fundamental law of higher education, the value of universities may change in different countries and in different historical periods [3]. However, higher education cannot follow the principle of maximization of enterprise profits and be completely market-oriented, nor can it become a tool for local governments to pursue political achievements. It is difficult for the enterprise profit-optimization model and the performance model of the government to be used to measure the influence of education on their unique output, i.e., innovation output.

Fourthly, in view of the particularity of universities in the innovation system, based on the innovation-system theory, this article, from the perspective of the differences in the quality of higher education, studies the relationship between universities and innovation by enterprises and regions, and explores the quality differences between colleges and universities and puts forward corresponding suggestions to promote the development of innovation.

\section{Literature Review}

Schumpeter (1926) proposed the concept of "innovation production function" [4] in 1926, and since then the modern innovation theory has expanded the extensional and connotative research of the original theory. Connotation research is to analyze the impact factors of relevant enterprises and markets that directly influence innovative products or services. The extensional research, namely, the comprehensive and relevant research on innovation system, is more inclined to policy evaluation and policy suggestions. The innovation-system theory proposed by scholars represented by Freeman [5] (1987) is inherently part of the extensional research. According to this theory, enterprises, governments, universities, and other organizations constitute a network system, whose comprehensive role determines the final innovation output [6]. The study of network system inevitably involves interdisciplinary research, and the study of influence relations between different departments inevitably involves departmental objectives. Given the foregoing, the relationship between universities and innovation demand is analyzed from the perspectives of economics and education.

First, beginning with the perspective of economics, enterprises hope to organically combine the elements beneficial to innovation for the purpose of increasing their profits, including human labor and material elements, namely, the human capital and scientific research results from institutions of higher learning [7]. However, the country (region) hopes to increase its innovation strength and make social progress. In other words, what entrepreneurs take aim at is profit statement while what the country (region) focuses on is the ranking list in terms of global innovation level. Enterprises hope to acquire the human capital and scientific research achievements that can serve practice, which are preferably directly aligned with production. Generally, students can be employed as soon as they graduate from universities and the achievements can be used as soon as they come out of laboratories. However, the improvement of the innovation ability of the country (region) is a systematic project, which needs to construct the cultivation of talent system and scientific research system characterized by the symbiotic relationship between the institutions of higher learning of various levels [8]. It is apparent that enterprises and the country (region) are engaged in production adjustment or strategic planning with the help of the signal release mechanism of higher education. The information of education quality released by institutions of higher learning is manifested in many forms, such as "the diploma signal"[9] and "university rankings." Based on the differentiation between information that is advantageous and that which is disadvantageous, enterprises and the country (region) choose the innovation-input elements that conform to their objectives in accordance with talent cultivation cost and research cost. That is to say, differentiated information is beneficial in helping information demanders to conduct screening and make choices [10].

Contrastingly, the quality signals and innovation demand goals released by universities should be compatible with each other before being beneficial to the realization of innovation synergy. The thinking characterized by paying equal attention to basic research on the part of innovation teams from research universities and the practical research conducted by application-oriented universities on the basis of the education-research framework is being gradually acknowledged by experts in educational circles [11]. In 2017, Suggestions of the Ministry of Education on the Setup of Higher Learning Institutions during the "13th Five-Year Plan Period," which was based on the orientation of talent cultivation, classified the higher education in our country into research-based, application-based, and vocational-technical categories. Theoretically speaking, such classification is helpful with regard to the target orientation on the part of universities. It also conforms to the law governing higher education and innovation synergy [12]. However, the knowledge of universities on the part of enterprises and government departments is always restricted to the university names printed in diplomas and the rankings of institutions of higher learning released by research institutions because these signals are easy to acquire and clear. Under the condition of utilizing the same set of evaluation index system [13], the existing information has already resulted in such understanding that research universities are of excellent quality, application-oriented universities are of ordinary quality, and vocational-technical universities are of the worst quality. Essentially speaking, this phenomenon has something to do with the mismatch between the classification of 
educational theories based on the characteristics of universities and the university quality evaluation system of economic system based on signal functions.

In addition, judging from the course of the influence of education quality on innovation, innovation is realized through the process of the knowledge spillover on the part of institutions of higher learning [14]. The existing studies have verified the following basic rules. (1) There is a positive correlation between the quality of higher education and innovation output. The total characteristics are embodied in the following two aspects. On the one hand, the action mechanism of the innovation facilitated by universities is realized by the accumulation of human capital. It is the universities that have promoted the improvement of workers' knowledge and skills and churned out special human capital and general human capital $[15,16]$, serving an important place for expediting the "knowledge development" [15] of the human beings. On the other hand, the scientific inventions from university-enterprise cooperation and research bases based on university-government cooperation are all the manifestations of knowledge externalization [16]. Specifically, the path of the action of universities in a geographical space on enterprise innovation is to provide "high-quality human capital" with additional increment of skills, and scientific research platforms or carry out scientific research cooperation, the consultation of innovative production management, or indirectly provide innovative services [17]. The knowledge imparted by higher education is beneficial to technological innovation [18]. Therefore, universities constitute an important source of external technology, and a sound investment in education can promote the absorption of knowledge and the dissemination of new technology [19], thus facilitating knowledge innovation. According to this law, the appropriateness of the differences between universities is based on a higher level of overall education quality. It is meaningless to study the differences at lower levels. (2) The appropriateness of the differences between universities is favorable to innovation. Based upon aggregated research, Lai Desheng and other scholars confirmed that too much or no quality difference between universities would weaken its positive impact on innovation. [20] Obviously, moderate differentiation is beneficial to competition, thus promoting knowledge spillover and improvement of innovation efficiency. If all universities were identical, the regional and enterprise innovation levels would not be very high because there would be no competitive mechanism by which to achieve the alignment between educational services and products and the government or enterprises. If the difference between universities is excessive, the innovation level will again be low because the appropriate difference between universities leads to the two-way flow of information and teacher resources. Such a flow gives rise to the collision of thoughts, which in turn triggers knowledge spillover and leads to the emergence of innovation,[17] and too great a difference between universities is, to some extent, likely to influence cooperative intelligence and even innovation. It is precisely because of the interrelation among the elements of the innovation system that resource allocation becomes particularly important. The investor of public education is the government[21], and the difference in education quality is closely related to the difference in resource allocation. Thus, the allocation of educational resources that gives consideration to fairness and efficiency is effective [19]. (3) Both the establishment of innovation partnership and the resource allocation are related to geographical space, and the geographical space in which knowledge spillover occurs can constrain the conditions. Innovation activities are related to geographical space, and the cost of knowledge transmission increases with the expansion of physical space. [22] The dissemination of knowledge and technology depends on the cooperation in the adjacent network. The more tacit knowledge is, the more important the spatial proximity of such knowledge will be. [23] This correlation between innovation and geographical space is also regarded as a kind of stickiness. Some scholars have studied the relationship between the spatial distribution characteristics of skilled workers and the distribution characteristics concerning the degree of university activity, believing there is a positive correlation between university research activities and the spatial aggregation degree of skilled workers [24].

In a word, enterprise innovation and national (regional) innovation are different in terms of target and path selection. There are differences in the response characteristics of university quality signals both at the government level and at the enterprise level. This is also the focus of the debate among education scholars such as Pan and Chiand Xue on whether it is more conducive to innovation to inherit the educational style of traditional academic universities [25] or make full use of the alignment mode [26] between universities and market demand. In fact, the convergence in the understanding of the law of innovation falls within the category of economics, while the quality evaluation and development mode selection of higher education belong to pedagogy. The rationale why such arguments have emerged lies in the single education quality evaluation system presented to the market, the government, and other demand sides of higher education services. Moreover, under the single evaluation system, research documents in the past did not conduct detailed research by sorting out the differences in innovation between enterprises and the country (region). This is the value based on the classification of the economics and pedagogical research framework and comparative research. Therefore, more detailed research is necessary. Specifically, the principle of rational allocation of resources ultimately determines the positive impact of the appropriateness of educational quality differences on innovation. Countries and regions are committed to improving the quality of higher education to achieve innovation-driven development [27]. Higher education promotes innovation through talent cultivation, scientific research, and social services. Although academic circles have similar understandings of the quality of higher education and innovation, from the perspective of educational output, the academic discussion and research on the difference of the quality of higher education based on the classification of the innovation demand between enterprises and countries (regions) need to be further conducted. 
The focus of this research is, based on the results of extensional research, to explore the difference in the influence of the difference in the quality of university operations on enterprise and regional innovation. Specifically, we hope to make breakthroughs in the following two aspects: First, does the difference in the quality of university operations have different influences on innovation of enterprises and countries (regions)? If so, how big is the difference? Second, since it is impossible for universities to follow the principle of maximization of enterprise profit and the principle of optimal government performance, how to realize the optimization of the innovation system composed of universities, enterprises, and the government by taking into account the difference in the innovation demand of enterprises and countries? Based on the above analysis, in the third part of this article, theoretical hypothesis is proposed and the characteristics of the influence of the difference in the quality of university operations on the innovation of enterprises and countries (regions) under the existing quality of university operations assessment system are analyzed. In the fourth part, the empirical research is carried out to test the hypothesis and calculate the size of the difference. In the fifth part, the conclusion is drawn and suggestions are given.

\section{Theoretical Hypothesis}

Under the model of traditional innovation, universities participate in innovation as the medium of scientific research material input and human capital input. Under the model of innovation system, higher education is independently considered as an influencing factor, which is a component of the innovation input-output model. The overall level of the quality of university operations and the level of differences jointly affect the innovation output. Sufficient discussion on higher education has been conducted in the existing research documents, which needs no further elaboration here. The differences and similarities of the interaction mechanisms between university innovation and enterprise innovation and between university innovation and regional innovation are compared.

(1) There are differences between enterprises and governments in behavioral goals and preferences for the attributes of innovation results. First, enterprises pursue profit maximization. Each and every enterprise hopes to improve its products or services through innovation so as to surpass other similar enterprises, occupy a higher market share, or even snatch a monopoly position. The bigger the difference in comparison with other competitors, the higher the excess profits are brought by monopoly. So an enterprise intends to pursue such difference, hoping that the universities cooperating with it can provide unique and monopolistic human capital and science and technology capital characterized by strong exclusiveness and weak externality. The optimal result is that except for the universities in cooperation with it, other universities do not have such monopoly capital.
To them, the heterogeneity of universities is the protection of excess profits in a disguised form. Second, the government does not want universities in different regions to operate at uneven levels. Instead, it is dedicated to forging a higher education system that is conducive to both the exertion of competitive mechanism and coordinated collaboration between universities, with the aim of promoting regional innovation and economic development. Because countries and regions have wider, more diverse demands for talents and scientific research, the externality of knowledge is beneficial for the overall development of countries and regions, which is embodied in the process of formulating the policy of national educational resource allocation. However, in a special historical period, the government may give priority to the development of some key institutions of higher learning due to the limitation imposed by constraints on key resources. However, while formulating the long-term policy, the country will take into consideration the negative impact of excessively tendentious allocation and moderately increase the investment in nonkey institutions of higher learning so as to make up for late-development resource defect.

(2) Enterprises and the government are different in their respective sensitivity to the signals from higher education. First, enterprises need signals with strong discrimination and sound differentiation, which are conducive to searching for the information favorable to innovation in a short time, including information about talent cultivation and scientific research achievements, so as to realize cost saving and efficiency promotion. Thus, the higher the differentiation of university quality evaluation scores, the more beneficial it is to enterprises. Accordingly, enterprises may, according to the signal of the quality of university operations (probably university rankings or the recognition of some rating agencies, etc.), take the initiative to contact universities. Whether the completion of industry-university-research cooperation, the purchase of patents to put them into production, or the hope to get high-quality human capital, enterprises will seek a way of cooperation by beginning with the purpose of profit maximization and even influence the behavior of universities in the process of the game between them and universities. For example, enterprises will, by bribing university administrators, make universities deviate from their goal of pursuing the best quality of university operations. However, university opening and university cooperation are important concepts of university development, and the contradiction between enterprise demand and university development becomes acute. Second, what the government needs are the signals with strong superposition and good integration degree. Such signals also include information about talent cultivation and scientific research results, which is conducive for integrating 
innovation resources and building an innovation system. If the investment subject of the university is the government, and the government is just short sighted, and the attention to the enterprise is higher than that to the higher education, it is believed that the innovation of the enterprise can increase the achievements in the short term and ignore the negative impact of the large difference in the quality of the university on the overall level of the quality of the university, and the long-term development of the university has a long-term effect on the innovation system. Then, in a nonindefinite game, the behavior of universities is likely to be under the sway of enterprises. In addition, compared with nonprofit universities, enterprises are an important source of financial revenue. The government is likely to be in cahoots with enterprises that pursue profit maximization, ultimately deviating from universities' goal of pursuing the optimization of quality increment. In this case, there may be a game between universities and the group composed of the government and enterprises. However, in general, at a higher stage of economic development, the government will set dual objectives, requiring both economic performance and educational performance, both of which are parallel and reinforce each other. Therefore, compared with enterprises, the signals with slightly weaker discrimination and slightly poorer differentiation can meet the demand of the government.

In a word, the difference in the quality of university operations that is most suitable for the innovation of the subsystem concerning the production of innovative products is different from that is most suitable for the national or regional subsystem of innovation. Although at a special stage of development, a country's emphasis on education may change, neither a nonshort-sighted government will not require universities to simply accumulate practical human capital and practical research as the fundamental development direction, nor will universities become the upstream industry for enterprises to achieve profit amplification, because this has poor effect on promoting the innovation driving force of the whole country. First, a country's innovation includes not only practical innovation beneficial to enterprise production but also basic innovation, while the overwhelming majority of enterprises will not invest in basic research with low profits, slow returns, and strong externality. Second, the effective operation of the innovation system cannot only depend on visible inventions and creations, which are only a result. The effective innovation mechanism, the reasonable innovation-related system, and the sound patent-protection law behind them cannot be accomplished by only depending on the innovation of enterprises. Making enterprises responsible for everything will inevitably lead to the increase of the cost of the whole society. Enterprises want to work with the universities that are as different from others as possible. However, this difference is only relative to the government. If the difference has affected the output of practical innovation of universities and even the profits of enterprises, enterprises will choose the multiuniversity cooperation mode or hope to moderately reduce the difference. The government wants the best degree of the difference between universities, whose boundary is the geographical scope under its jurisdiction which can be benefited by the external profits after the improvement of the quality of university operations. On the other hand, universities have their own unique value system, so they can improve the quality of education through competition, learning, and cooperation with other universities. Therefore, in the "three helix" system, universities, enterprises, and the government not only influence each other but also have their respective relationship. A schematic diagram (Figure 1) is used to describe the above theoretical relationship.

Based on this, this article proposes the following research hypothesis: the influence of the difference in the quality of higher education on the innovation level of enterprises and countries (regions) is different. Under the same judgment criterion, in comparison with the coefficient of the difference in the quality of university operations that is most beneficial to regional innovation, the coefficient of the difference in the quality of university operations that is most suitable for the production of enterprise innovation is higher. Specifically, in the same administrative region, under the premise that the overall level of the quality of university operations is unvarying, the big difference in the quality of university operations is more conducive to the effective screening of information and to the improvement of innovation efficiency on the part of enterprises in the process of innovation element allocation. The small difference in the quality of university operations is more conducive for the rapid mobilization of resources and for the improvement of innovation level on the part of countries (regions) in the process of innovation system construction.

\section{Empirical Test}

Technically, the descriptive analysis based on existing research data is strong in intuition, but it has the following defects. First, it is impossible to control the influence of other factors to analyze the problem. Second, although the data from the alumni association is highly reliable and has become an important reference for education evaluation, college entrance examination and postgraduate entrance examination, the comprehensive evaluation process is often affected by subjective factors, so it is necessary to verify its reliability. Therefore, it is meaningful to discuss the data characteristics and trends with the help of an econometric model and give the deterministic coefficient of the quality of university operations gap which is suitable for the innovation of enterprises and countries (regions).

4.1. Data, Variables, and Model Selection. In order to further confirm the theoretical hypothesis, empirical analysis is made with the help of the data from the Listed Shenzhen GTA Education Tech Ltd., China National Intellectual Property Administration, as well as China Statistical 


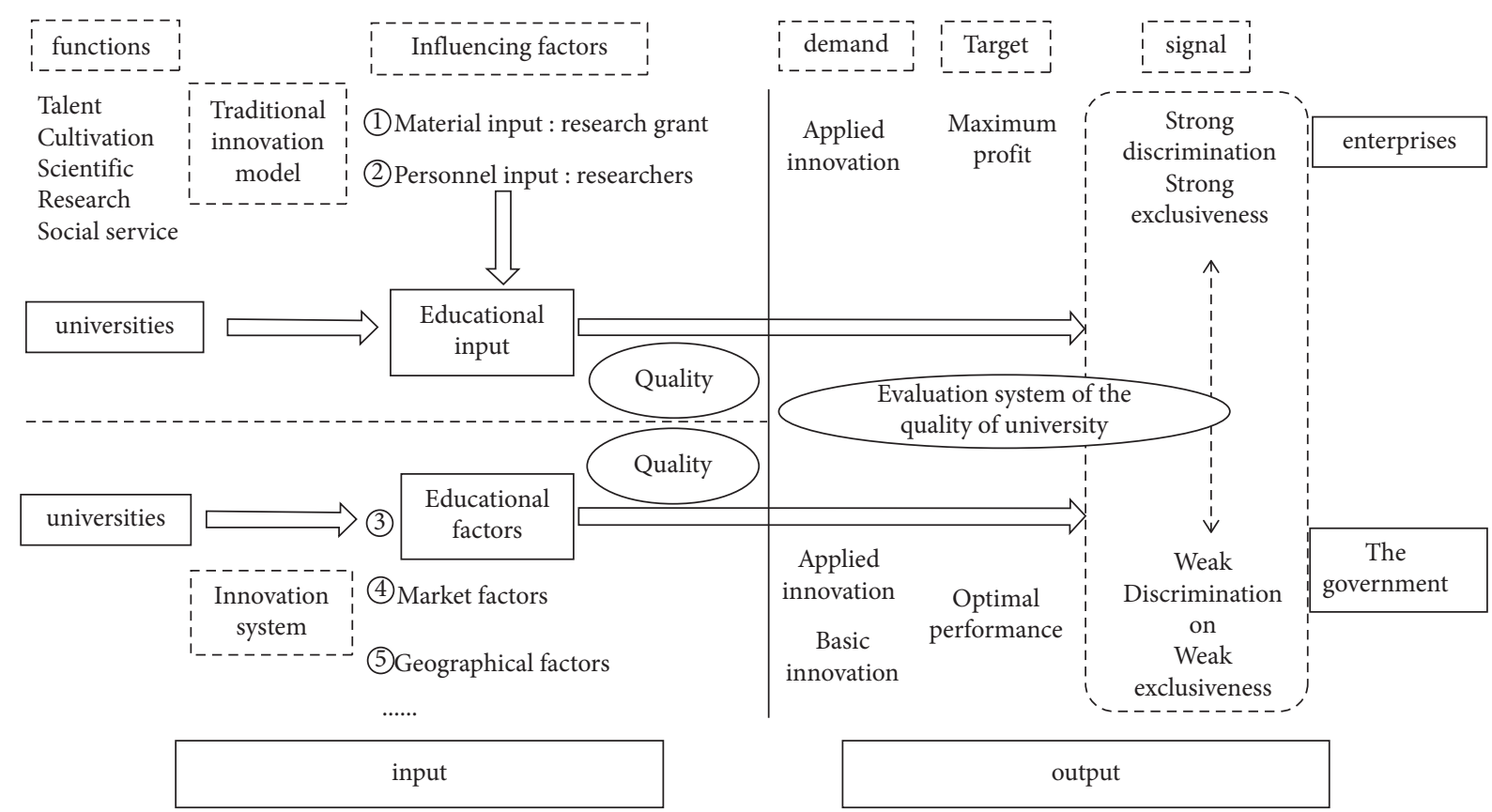

FIgURE 1: Theoretical framework.

Yearbook on Science and Technology and China Statistical Yearbook released by the National Bureau of Statistics and the scoring of the university rankings published by http:// www.cuaa.net/ from 2013 to 2017.

\subsubsection{Selection of Data and Variables}

(1) Selection of Explained Variables. In the enterprise model and the regional model, the number of patents per capita of each enterprise or each province, municipality directly under the Central Government or autonomous region in China was selected as the explained variable, respectively. First, when studying innovation output, an ideal method of selecting explained variables is to make a scientific and reasonable comprehensive evaluation of all indicators that can measure innovation output and design the model by taking the comprehensive evaluation indicators as dependent variables. However, according to the current data, all the institutions measuring China's innovation index almost without exception put the innovation output and input into the comprehensive index evaluation system when conducting the index compilation. For example, the Innovation Capability Index [28] compiled by the Research Group of the Chinese Academy of Science and Technology for Development evaluates the regional innovation level from several aspects such as knowledge creation, knowledge acquisition, enterprise innovation, and innovation environment. Each secondary comprehensive index contains a single index of innovation output and innovation input. Obviously, from the demand of the government and other relevant departments, such a design is reasonable. However, putting such comprehensive indicators into the model as dependent variables will lead to the wrong logic characterized by explaining comprehensive indicators with a single indicator of comprehensive indicators. Apparently, this method is inadvisable.

Second, we can consider designing the comprehensive index of innovation output by ourselves to conduct the evaluation, but this is of little influence on the core research issues of this article and the evaluation effect may not be good. On the one hand, this article hopes to investigate the influence of the range of quality among universities on innovation output, instead of focusing on the comprehensive evaluation of innovation output indicators, and the independent comprehensive evaluation design can be safely taken as a new research direction. On the other hand, the most critical part of comprehensive evaluation is the weight design because different weight designs will produce significantly different evaluation results, and an unscientific design will greatly reduce the objectivity of the conclusion. According to the calculation method of Annual China Innovation Index (CII) issued by National Bureau of Statistics, this article calculates the composite index of the collected regional data with equal weight method and confirms that there is little difference between the results obtained from the composite indexes as explained variables and those obtained from a single index. Judging from the issue of studying whether the range of quality among universities has an influence on regional innovation, calculating the comprehensive index is not necessarily more advantageous than directly using a single index as a proxy variable in measurement because the description of the innovation characteristics of enterprises and countries (regions) will become less comparable due to the establishment of the comprehensive index.

(2) Selection of Explanatory Variables. First, in terms of enterprises, the research on the correlation between their 
innovation level and education in the previous research documents is mainly the analysis of the research and development cooperation between universities and enterprises as well as the quantity and quality of scientific research input on the part of enterprises, based on the law that knowledge transmission cost increases with the increase of physical space [29]. This article, with the help of data from China's listed companies, verifies this issue, to the exclusion of the samples in the form of "R\&D expense" that are clearly stated in the financial statements of real estate enterprises and the like, and that are not applicable to the enterprise before obtaining the data of a total of 1,648 listed companies, accounting for approximately $70 \%$ of the total number of listed companies. The range of quality among universities in the province where the enterprises are located is taken as the main explanatory variable. It should be noted that, in order to be comparable with the research at the national (regional) level, the quality score data of the ranked universities published by the Alumni Association is adopted here, with the Gini Coefficient and the quadratic term of the Gini Coefficient used for measuring the differences in quality between universities.

In addition, variables are designed in the model control from aspects such as material capital input, human capital input, enterprise characteristics, economy, and investment environment of the region where enterprises are located. First, the ratio of enterprise development expenditure to enterprise year-end capital is used to measure enterprise R\&D capital investment. Although the Accounting Standard in 2007 stipulated that the new method should be adopted in accounting the R\&D expenditure of an enterprise, many enterprises have reported that the item is 0 or vacant. There are two reasons for this phenomenon: (1) it is enterprise nature that determines financial accounting. For example, enterprises engaged in real-estate development directly indicate "not suitable for reporting R\&D expenditure" in the report; (2) patents are no longer included in the researchand-development expenditure after they are transformed into products. Some enterprises can find the number of their patents in the Patent Office, but in their financial statements, the record development expenditure or research-and-development expenditure is still recorded as zero. This shows that patent application has been completed, but the cost of research and development projects is not calculated, which has something to do with the Accounting Standard before 2007 that did not require that $R \& D$ expenditure should be reported. Therefore, using the capital invested by an enterprise as an explanatory variable can, to some extent, supplement the items not included in the $R \& D$ input. Second, both the proportion of the staffs on $\mathrm{R} \& \mathrm{D}$ positions and that of senior executives who are graduates of "Project 211 " and "Project 985" key universities are considered as variables in the measurement of the enterprise's input of innovation personnel. Among them, the proportion of $\mathrm{R} \& \mathrm{D}$ personnel represents the overall $R \& D$ human capital input of the enterprise, and the proportion of senior executives who are graduates of "Project 211" and "Project 985" key universities represents the influence of high-quality talents on the enterprise's innovation-management decision- making. Third, per-capita GDP and the turnover of patents in the region where the enterprise is located are used as control variables to describe the economic environment and investment environment of the region where the enterprise is located. Fourth, the number of years since the enterprise went public and the initial capital at the time of going public are used as variables to describe the characteristics of enterprises. Variable description is shown in Table 1:

Second, as far as a country (region) is concerned, the main explanatory variable is the range of quality among universities. In order to make a comparison with the enterprise model, the Gini Coefficient indicating the score from university quality evaluation and the square of the Gini Coefficient are also selected as explanatory variables. The control variables are mainly considered from the aspects such as the input of material capital, the input of human capital, environment of innovative economy, and innovation market conditions. (1) The capital investment is represented by per-capita yearly total internal expenditure for scientific and technological activities (AR\&DK) in each province. According to the index interpretation of China Statistical Yearbook on Science and Technology, the total annual internal expenditure for scientific and technological activities in each province includes Basic Research, Applied Research, and Experimental Development. (2) The number of the annual full-time personnel in research and experimental development (R\&DL) in each province is used to represent the investment of human capital in innovation activities. Specifically, the term "annual full-time R\&D personnel" refers to the personnel whose workload of R\&D activities is more than 0.9 year (including 0.9 year) during the period of reporting. (3) The situation of the environment of regional innovative economy (AGDP) is represented by per-capita GDP in each province. Obviously, to some extent, the level of economic development will influence the total innovation output of a region. Therefore, this article also adds per-capita GDP into the control variables to test the conspicuousness of explanatory variables. (4) The marketization degree index (MAR) is used to represent the market conditions of innovation because the market maturity of a region often influences innovation results or output. In the region with high market maturity, great competitive pressure exists among institutions, especially among enterprises. This pressure may compel enterprises to innovate. The index controlling the marketization degree [30] of each province (municipality, autonomous region) represents the market conditions of innovation and conducts econometric tests. Variable description is shown in Table 2:

4.2. Measurement of the Differences in Quality between Universities. Many scholars have evaluated and analyzed the reasons for the absolute difference in the quality level of universities in different regions of China, and the main conclusions are "big difference" and "imbalance." In addition, there are authoritative institutions that have carried out comprehensive evaluations of the quality level of the universities in various regions. Undoubtedly, the absolute difference between regions is an important issue worthy 
TABLE 1: The selection and description of enterprises' variables.

\begin{tabular}{|c|c|c|}
\hline \multicolumn{2}{|c|}{ Variable names } & Variable description \\
\hline Explained variable & Ap & $\begin{array}{l}\text { Per-capita number of invention patents (obtained by dividing the year-end number of employees on the } \\
\text { payroll by the annual number of invention patents of the enterprise) }\end{array}$ \\
\hline $\begin{array}{l}\text { Explanatory } \\
\text { variables }\end{array}$ & $\begin{array}{l}\text { Gini } \\
\text { Gini }^{2}\end{array}$ & $\begin{array}{l}\text { Gini coefficient indicating the score of the quality of a university } \\
\text { The square of Gini Coefficient indicating the score of the quality of a university }\end{array}$ \\
\hline \multirow{6}{*}{ Control variables } & $\begin{array}{l}\mathrm{R} \& \mathrm{D} \\
\text { ratio } \\
\mathrm{R} \& \mathrm{D} \\
\text { staff }\end{array}$ & The proportion of the development expenditure in the closing assets of the enterprise \\
\hline & $M$ ratio & $\begin{array}{c}\text { The proportion of the graduates of "211 Project" and "985 Project" key universities in the senior executives } \\
\text { of the enterprise }\end{array}$ \\
\hline & AGDP & $\begin{array}{c}\text { The per-capita GDP of the province (municipality directly under the central government or autonomous } \\
\text { region) where the enterprise is located }\end{array}$ \\
\hline & Trade & $\begin{array}{l}\text { The transaction amount of the patents in the province (municipality directly under the central } \\
\text { government or autonomous region) where the enterprise is located }\end{array}$ \\
\hline & & The number of years since the enterprise went public \\
\hline & Capital & The registered capital of the enterprise \\
\hline
\end{tabular}

Note. The Gini Coefficient has been proved to be consistent with other indicators in the preceding part of the article. In order to be consistent with the theoretical model mentioned above, an analysis is made by mainly resorting to the Gini Coefficient.

TABLE 2: Selection and description of regional variables.

\begin{tabular}{|c|c|c|}
\hline & $\begin{array}{c}\text { Variable } \\
\text { names }\end{array}$ & Variable descriptions \\
\hline \multirow{3}{*}{$\begin{array}{l}\text { Explained variable } \\
\text { Explanatory } \\
\text { variables }\end{array}$} & $A p$ & Per-capita number of patents (unit: ten thousand people per patent) \\
\hline & Gini & Gini Coefficient, indicating the score of the quality of a university \\
\hline & $\mathrm{Gini}^{2}$ & The square of Gini Coefficient, indicating the score of the quality of a university \\
\hline \multirow{5}{*}{ Control variables } & AR\&DK & $\begin{array}{l}\text { per-capita yearly total internal expenditure for scientific and technological activities (unit: yuan per } \\
\text { person) }\end{array}$ \\
\hline & $R \& \mathrm{DL}$ & $\begin{array}{l}\text { The number of the annual full-time personnel in research and experimental development (unit: year. } \\
\text { people) }\end{array}$ \\
\hline & AGDP & Per-capita GDP (unit: 100 million yuan) \\
\hline & MAR & Marketization degree index \\
\hline & MSC & $\begin{array}{l}\text { The average score of the composite scores of the quality of universities in a province (provincial-level } \\
\text { municipality or autonomous region) }\end{array}$ \\
\hline
\end{tabular}

studying, because the quality level of universities in different regions will influence the cultivation of talent, scientific research, and social services of the innovation system, which is also regarded as an important control variable influencing the overall level of the innovation in various regions. However, the relative difference also remains to be further explored so as to coordinate the research on the absolute difference.

Similar to previous studies [31], the measurement results from university ranking institutions are used as proxy variables to evaluate the quality level of universities. In terms of university rankings, top universities such as Tsinghua University and Peking University changed very little, but more than $70 \%$ of institutions of higher learning have changed more than 10 places in the past five years, including key institutions and ordinary ones. In this article, the Gini Coefficient and standard deviation of the comprehensive scores of all listed universities are calculated with the help of the data from http://www.cuaa.net/ to evaluate the level of the range of quality among universities. It should be noted that in addition to Gini Coefficient, standard deviation is also given here. The purpose is to compare different indicators measuring the difference and verify the reliability of the results. As shown in Figure 2, the Gini Coefficient indicating the score of the quality of universities and the standard deviation result are consistent. In other words, provinces with a higher Gini Coefficient have a higher standard deviation coefficient and there is little relative difference between the two indicators.

Specifically, the Gini Coefficient of the scores of the quality of the universities in Jilin, Anhui, and Zhejiang provinces exceeds 0.8, and that in Fujian, Guangdong, Sichuan, Shandong, and Gansu exceeds 0.75. Although these regions have different levels of economic development, each of them has one or two high-quality universities "taking the lead," and other universities "find it hard to approach them." We might as well make a comparison by using the number of "985 Project" and "211 Project" key universities. Jilin, Anhui, or Zhejiang has only one "985 Project" key university. Moreover, the number of " 211 Project" key universities in each of the three provinces is small. Of them, Jilin and Anhui have two such universities. The Gini Coefficient of the scores of the quality of the universities in Qinghai, Ningxia, and Tibet is less than 0.45 , and that in Jiangxi, Tibet, and Xinjiang 


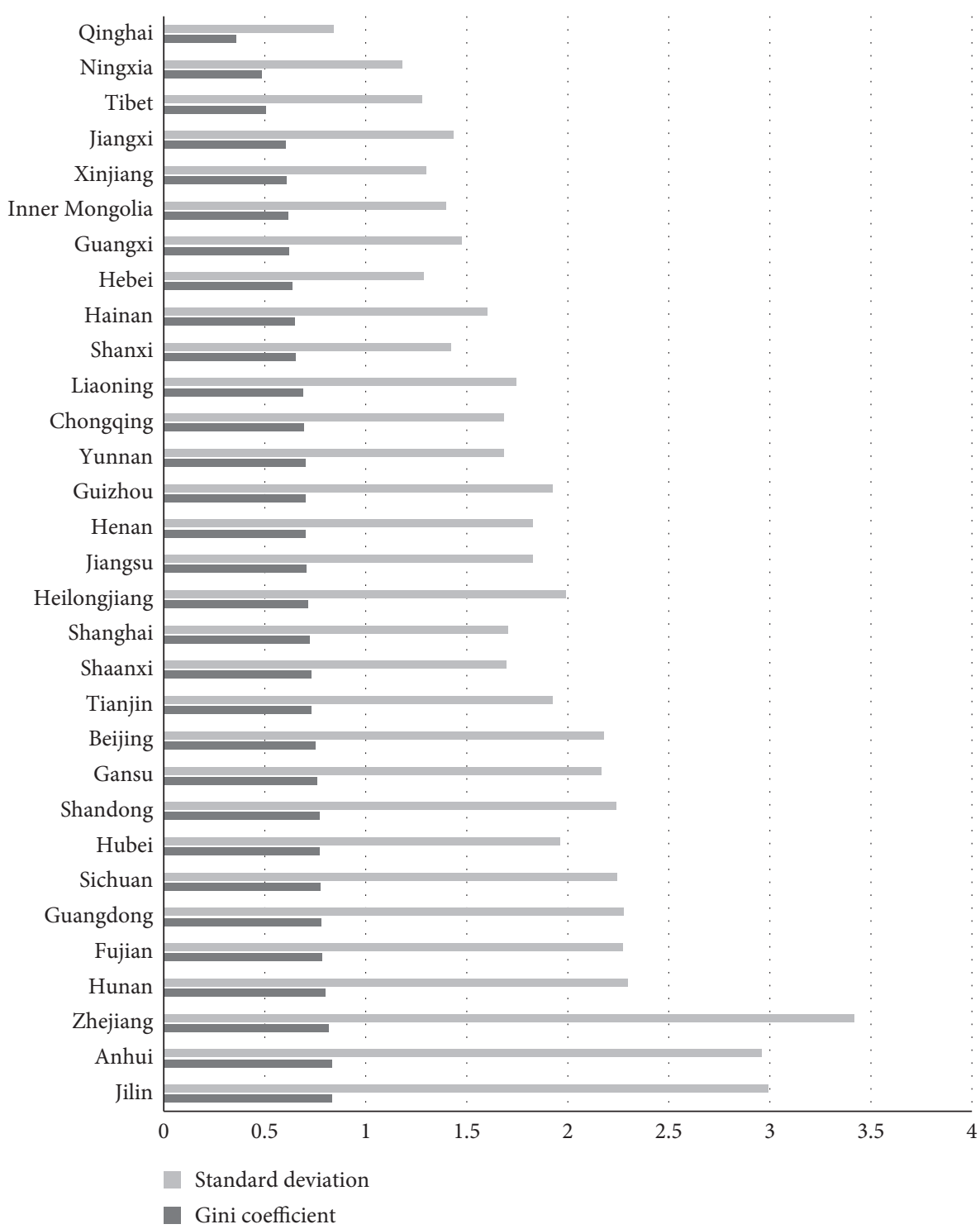

Figure 2: Difference coefficients of the quality of universities in the provinces, provincial-level cities, and autonomous regions on the Chinese mainland. Note. In this figure, rankings are made according to the Gini Coefficients of the scores. Data source: http://www.cuaa.net/ . In terms of data calculation, the result is the average value in five years.

is less than 0.5. Accordingly, there are no "985 Project" key universities in these regions, and even the number of " 211 Project" key universities in the regions is extremely small. In addition, judging from the overall level of education in various regions, Beijing, Shanghai, Jiangsu, and other provinces with the overall comparatively excellent quality of universities are not in the ranks of an excessively high or excessively low coefficient of the quality difference among universities.

4.3. Quantitative Analysis and Robustness Test. In view of the selection of panel data for analysis and the selection of the abovementioned variables, the design model is as follows:

$$
Y_{l t}=\alpha_{l}+\beta_{1} G_{l t}+\beta_{2} G_{l t}^{2}+\beta_{z}^{\prime} Z+\mu_{l t},
$$

where $t$ represents time (year), $l$ signifies region, $\alpha_{l}$ stands for the intercept term, $\beta$ indicates the coefficient of the main explanatory variable, $\beta$ denotes the coefficient vector of the control variable, and $\mu_{l t}$ is the random disturbance term.

First, based on the analysis of the characteristics of the kernel density function as the per-capita number of patents of the explained variable, it is not difficult to find that the distribution of the per-capita number of patents is not normal, and displays integral and nonnegative properties. The variance determines that the counting panel data model is more suitable for the research design in this article. In conducting the concrete empirical test, the least-square method will also be used for model estimation in this article, so as to make a contrast with the model selection. Second, based on the simple descriptive statistics of variables, it is not difficult to find that the average per-capita number of patents is less than the corresponding standard deviation, presenting a discrete feature, which further confirms the rationality of the selection of the model of counting panel data. If the 
hypothesis is true, the $\beta_{2}$ coefficients obtained from countrylevel data and enterprise-level data are significantly different from each other. The schematic diagram is shown in Figure 3.

4.3.1. Preliminary Analysis of Models. Based on the preliminary analysis that is made in accordance with the traditional input-output model of innovation, it is believed that the innovation output is affected by two factors: innovation material input and personnel input. Concurrently, the main explanatory variable and other two variables such as the coefficient of the quality difference among universities and its square are incorporated in the model.

(1) Enterprise Model. Because the period of data interception is from 2013 to 2020 together with the fact that different enterprises were listed at different times, the data structure is unbalanced panel data. In the process of constructing the model, after adding variables, for example, the proportion of enterprise development expenditure in the closing assets, the number of companies is reduced to 2,485 due to some missing values, which, however, still accounts for $65 \%$ of the total number of listed companies as the samples to be studied. In this article, the knowledge innovation function is used to conduct the fitted calculation. The data have the characteristics such as a large sample size and a short period of time. Based on the Hausman test conducted on the model, the Chi-square value thus obtained is 0.14 and the corresponding $p$-value is 0.71 , indicating that the random effect model is more suitable for the data. With the help of the model, it is not difficult to find (see Table 3 ) that the introduction of different control variables has little influence on the coefficient values of Gini and $\mathrm{Gini}^{2}$ variables, and the coefficients are noticeable at the level of $1 \%$. Through calculation, it can be known that the Gini Coefficient value corresponding to the "inverted U-shape" vertex calculated by the quadratic equation is approximately 0.75 .

The level of the difference in quality between the universities within a region does have a certain influence on enterprise innovation, displaying a remarkable "inverted U" trend. With other conditions unchangeable, the innovation ability of the regions where the quality level of universities is generally backward is also poor, while that of the regions whose overall quality levels are not low but do not have a particularly significant inter-university difference is strong. The innovation ability of the regions whose overall quality levels are not low but have a big inter-university difference will be negatively influenced. In addition to such microscopic evidence, some other variables of the model are also consistent with economic, statistical significance. The proportion of enterprise development investment, the proportion of $\mathrm{R} \& \mathrm{D}$ personnel, the proportion of senior executives graduating from key universities, and the percapita GDP of each region have a significant positive influence on innovation. Such a result is basically consistent with the reality. First, an enterprise has a strong R\&D ability if it invests a lot in research and development and has rich human capital. Second, the proportion of the graduates of
“211 Project" and "985 Project" key universities in senior executives has a prominent influence on enterprise innovation, which indicates that enterprise innovation is closely related to the educational background of managers. It also confirms the important role played by quality institutions of higher learning in management talent cultivation from a sideways perspective. Third, areas with good economic development are relatively mature and perfect in infrastructure construction, consumer market, and other aspects, which is conducive to enterprise innovation activities. Furthermore, the influence of initial capital on innovation is significantly negative, which is related to the emergence of a large number of listed high-tech companies. Compared with traditional industrial manufacturing enterprises, the registered capital of high-tech companies is not high at the initial stage of being listed, and they mainly rely on their innovation ability to expand profits and improve their capital stock after going public.

(2) Regional Model. Given the data characteristics related to individual characteristics and explanatory variables, in this article the random effect model is selected. The Chi-square value of 7.72 is obtained through the Hausman test, which accepts the hypothesis of using the random effect model at a significance level of $1 \%$. Table 4 shows the estimation results of the simple linear model obtained by the least-square method and the counting panel data model obtained by the GMM method.

According to the result of the model in Table 4, the value of the Gini Coefficient of the quality of an optimal university conducive to regional innovation ranges from 0.45 to 0.65 , which is smaller than the result of the enterprise model. Obviously, the hypothesis proposed in this article has been verified. In other words, the range of quality among universities that is conducive to enterprise innovation and that is conducive to national (regional) innovation are different, and the former is higher than the latter. Once the control variables are added, the difference between coefficients is relatively big while the difference between the Gini Coefficient values corresponding to the optimal inflection point of the model is not big, ranging from 0.45 to 0.65 . Compared with the comprehensive score, the range of quality among universities in provinces such as Anhui, Zhejiang, and Guangdong is so big as to influence innovation. The range of quality among universities in provinces such as Qinghai, Ningxia, and Tibet is excessively small, which leads to a low innovation level. The range of quality among universities in provinces like Jiangsu is moderate, which, if continuing to expand, may influence innovation level.

In addition, some conclusions in research documents have also been verified. First, the "inverted U" hypothesis has been proved. The empirical results show that all the quadratic coefficients of the scores concerning the quality of university operations are less than 0 and significant at the level of $1 \%$. After the addition of control variables, the value of the model coefficient changes only slightly, and the significance of the model coefficient does not decrease. It is shown that when other variables remain unchanged, the quadratic equation presents the feature of a downward opening. In other words, there is an "inverted U-shape" 


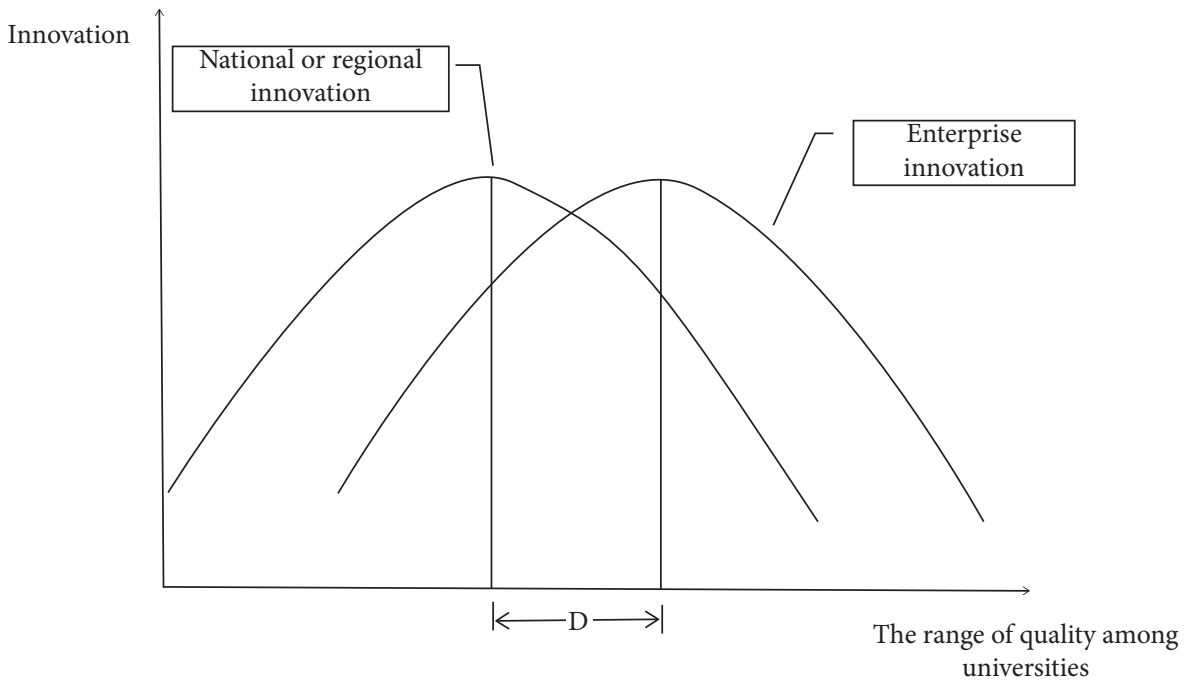

FIgURE 3: Hypothesis of the relationship between the quality difference between universities and innovation. Note. In thefigure, “ $D$ ” denotes the relative amount of differences in quality between universities that are most conducive to national (regional) and enterprise innovation.

TABLe 3: Preliminary analysis and test of enterprise model.

\begin{tabular}{|c|c|c|c|c|c|}
\hline Variables & $\begin{array}{l}\text { Model 1-1 } \\
\text { OLS }\end{array}$ & $\begin{array}{l}\text { Model 1-2 } \\
\text { Poisson panel } \\
\text { (RE) }\end{array}$ & $\begin{array}{l}\text { Model 1-3 } \\
\text { Poisson panel } \\
\text { (RE) }\end{array}$ & $\begin{array}{l}\text { Model 1-4 } \\
\text { Poisson panel } \\
\text { (RE) }\end{array}$ & $\begin{array}{l}\text { Model } 1-5 \\
\text { Poisson panel } \\
\quad(\mathrm{RE})\end{array}$ \\
\hline $\begin{array}{l}\text { Coefficients of the difference in quality between } \\
\text { universities }\end{array}$ & $\begin{array}{c}14.400^{* * *} \\
(5.005)\end{array}$ & $\begin{array}{c}20.439^{* * *} \\
(5.915)\end{array}$ & $\begin{array}{l}28.535^{* * *} \\
(5.401)\end{array}$ & $\begin{array}{c}27.135^{* * *} \\
(6.247)\end{array}$ & $\begin{array}{c}27.203^{* * *} \\
(6.120)\end{array}$ \\
\hline $\begin{array}{l}\text { Square of the coefficients of the difference in } \\
\text { quality between universities }\end{array}$ & $\begin{array}{c}-7.551^{* *} \\
(3.648)\end{array}$ & $\begin{array}{c}-11.987^{* * *} \\
(4.253)\end{array}$ & $\begin{array}{c}-19.200^{* * *} \\
(3.899)\end{array}$ & $\begin{array}{c}-18.108^{* * *} \\
(4.465)\end{array}$ & $\begin{array}{c}-18.201^{* * *} \\
(4.381)\end{array}$ \\
\hline $\begin{array}{l}\text { Proportion of enterprise development } \\
\text { expenditure in general closing assets }\end{array}$ & & & $\begin{array}{c}6.003^{* * *} \\
(0.414)\end{array}$ & $\begin{array}{c}5.329^{* * *} \\
(0.512)\end{array}$ & $\begin{array}{c}5.337^{* * *} \\
(0.512)\end{array}$ \\
\hline $\begin{array}{l}\text { Proportion of the personnel on } \mathrm{R} \& \mathrm{D} \text { positions } \\
\text { in the enterprise }\end{array}$ & & & $0.426^{* * *}(0.028)$ & $0.367^{* * *}(0.029)$ & $0.350^{* * *}(0.029)$ \\
\hline $\begin{array}{l}\text { Proportion of the graduates of " } 211 \text { Project" and } \\
\text { "985 Project" key universities in senior } \\
\text { executives in the enterprise }\end{array}$ & & & $\begin{array}{c}0.144^{* * *} \\
(0.054)\end{array}$ & $\begin{array}{c}0.359^{* * *} \\
(0.055)\end{array}$ & $\begin{array}{c}0.372^{* * *} \\
(0.055)\end{array}$ \\
\hline $\begin{array}{l}\text { Per-capita GDP of the province where the } \\
\text { enterprise is located }\end{array}$ & & & & $\begin{array}{c}0.277^{* * *} \\
(0.004)\end{array}$ & $\begin{array}{c}0.277^{* * *} \\
(0.004)\end{array}$ \\
\hline $\begin{array}{l}\text { The turnover of the patents in the province } \\
\text { (provincial-level city or autonomous region } \\
\text { where the enterprise is located) }\end{array}$ & & & & $\begin{array}{c}-0.094^{* * *} \\
(0.032)\end{array}$ & $\begin{array}{c}-0.119^{* * *} \\
(0.032)\end{array}$ \\
\hline Number of years after the enterprise went public & & & & & $\begin{array}{l}-0.008 \\
(0.007)\end{array}$ \\
\hline Registered capital of the enterprise & & & & & $\begin{array}{c}-0.678^{* * *} \\
(0.180)\end{array}$ \\
\hline Cons & $\begin{array}{l}-2.592^{* * *} \\
(0.971)\end{array}$ & $\begin{array}{c}-5.433^{* * *} \\
(2.059)\end{array}$ & $\begin{array}{c}-8.360^{* * *} \\
(1.875)\end{array}$ & $\begin{array}{c}-8.731^{* * *} \\
(2.193)\end{array}$ & $\begin{array}{c}-8.471^{* * *} \\
(2.148)\end{array}$ \\
\hline$N$ & 16193 & 16193 & 14647 & 14638 & 14638 \\
\hline Wald $\mathrm{chi}^{2}$ & 7.46 & 254.64 & 492.54 & 5197.85 & 8451.83 \\
\hline$P$ & 0.024 & $\leq 0.001$ & $\leq 0.001$ & $\leq 0.001$ & $\leq 0.001$ \\
\hline
\end{tabular}

Note. 1 . The values outside and inside the parentheses represent estimated coefficients and standard errors, respectively; ${ }^{*},{ }^{* *}$, and ${ }^{* * *}$ represent significance levels of $1 \%, 5 \%$, and $10 \%$, respectively. 2 . Limited by page width, the text description of explanatory variables and control variables is not listed. The specific comparison is shown in Table 1.

trend. It should be noted that, compared with the enterprise model, the Gini Coefficient and its square of the score of the quality of university operations from the coefficients of the major explanatory variables of the regional model based on macro data are slightly less significant, which just confirms the conclusion that the signal of the quality of university operations required by regional innovation is weak in terms of the discrimination degree.

Second, the coefficient value of per-capita internal expenditure for activities involving science and technology is negative but not significant, which cannot confirm that the result is contrary to the general economic significance. 
TABle 4: Preliminary empirical results of the macro data model.

\begin{tabular}{|c|c|c|c|c|c|}
\hline \multicolumn{2}{|r|}{ Model } & $\begin{array}{c}\text { Model 2- } \\
1\end{array}$ & Model 2-2 & Model 2-3 & Model 2-4 \\
\hline \multirow{5}{*}{$\begin{array}{l}\text { Explanatory } \\
\text { variables }\end{array}$} & & OLS & $\begin{array}{l}\text { Poisson panel } \\
\text { (RE) }\end{array}$ & $\begin{array}{l}\text { Poisson panel } \\
\text { (RE) }\end{array}$ & $\begin{array}{l}\text { Poisson panel } \\
\text { (RE) }\end{array}$ \\
\hline & Coefficient of the range of quality among & 36.041 & $7.604^{*}$ & $7.675^{*}$ & $8.005^{*}$ \\
\hline & universities & $(24.208)$ & $(4.427)$ & $(4.467)$ & $(4.467)$ \\
\hline & Square of coefficient of the quality difference among & $-39.510^{*}$ & $-5.796^{*}$ & $-5.889^{*}$ & $-8.889^{* *}$ \\
\hline & universities & $(22.103)$ & $(3.459)$ & $(3.450)$ & $(3.492)$ \\
\hline \multirow{7}{*}{ Control variables } & $\begin{array}{l}\text { Internal expenditure for activities involving science } \\
\text { and technology }\end{array}$ & & & $\begin{array}{l}-4.243 \\
(9138)\end{array}$ & -3.675 \\
\hline & and technology & & & $\begin{array}{c}(9.138) \\
0.764^{* * *}\end{array}$ & $\begin{array}{c}(8.141) \\
0.164^{* * *}\end{array}$ \\
\hline & The number of full-time R\&D personnel & & & $(0.007)$ & $(0.015)$ \\
\hline & Per-capita GDP & & & & $\begin{array}{l}8.638^{* *} \\
(4.617)\end{array}$ \\
\hline & Index of marketization degree & & & & 1.588 \\
\hline & & 2.257 & -1.263 & -1.172 & $\begin{array}{l}(1.371) \\
1.602\end{array}$ \\
\hline & Constant term & $(7.744)$ & $(2.357)$ & $(1.505)$ & $(1.314)$ \\
\hline \multirow{3}{*}{ Statistics of models } & $N$ & 246 & 246 & 246 & 246 \\
\hline & Wald $\mathrm{chi}^{2}$ & 3.481 & 35.370 & 139.315 & 174.832 \\
\hline & $P$ & 0.175 & $\leq 0.001$ & $\leq 0.001$ & $\leq 0.001$ \\
\hline
\end{tabular}

Note. 1 . The values outside and inside parentheses represent estimated coefficients and standard errors, respectively; ${ }^{*},{ }^{* *}$, and ${ }^{* * *}$ represent significance levels of $1 \%, 5 \%$, and $10 \%$, respectively.

Moreover, the number of full-time R\&D personnel is significantly positive, which indicates that human input is more important than material input in regional innovation. In addition, this has some connection to the selection of indicators. There is a correlation between the number of annual full-time R\&D personnel and the amount of percapita internal expenditure for activities involving science and technology.

\subsubsection{Robustness Test of Models}

(1) Robustness Test of Enterprise Model. In the process of the enterprise data analysis above and the model test in this section, we have found several problems as follows:

First, the provinces with higher educational scores, such as Beijing, Shanghai, and Jiangsu, have higher places in innovation rankings, while the gap between the educational levels of the institutions of higher learning in these provinces happens to be smaller. Is it because the score of the quality of university operations instead of the Gini Coefficient of the score has an influence on innovation? Therefore, in this article, the model is estimated once again by adding the variable in the form of Allsc, which represents the overall educational level in the province or city where the enterprise is located.

Second, through the empirical analysis described in this section, it has been found that the overall level of the quality of institutions of higher learning in some provinces-such as Hebei and Shanxi-is generally not high but the innovation ability is not significantly poor. Previous studies are characterized by taking administrative division as the limitation of regional geographical characteristics, assuming that the exchange and benefit spillover between universities in different administrative regions is remarkable. Now, the assumption is relaxed and the influences of knowledge spillover from neighboring areas or inter-regional scientific research cooperation are differentiated. First, set the dummy variable as D11, and combine Beijing, Shanghai, Jiangsu, Guangdong, and Zhejiang, the top five in the ranking of the comprehensive indexes of innovation with 1 placed on provinces such as Hebei, Jiangxi, and Guangxi, each of which has not more than two "985 Project" or "211 Project" key universities, and other provinces are marked 0. Second, set the dummy variable to be D12, and fix the label 1 on Hebei, Shanxi, Henan, Jiangxi, and Guangxi, which are the top five in innovation ranking, whose straight line distance is within $1000 \mathrm{~km}$ and each of which has not more than two "985 Project" or "211 Project" key universities, and the other provinces are indicated as "0." Based on the above two points, the model is estimated again, and the results are shown in Table 5. The following conclusions can be drawn:

First, the Gini Coefficients of the differences in the scores of quality between universities, which correspond to the lowest point of "inverted U line," range between 0.73 and 0.8 . Once the control variable is added, while the coefficients of explanatory variables Gini ${ }^{2}$ and Gini do not change significantly, it remains significant. Concurrently, under the given premise of the other variables, the Gini value corresponding to the lowest point of the quadratic curve is stable, thus statistically proving that in spite of taking into consideration the overall level of education on the part of the universities in the provinces and cities, knowledge spillover, and interregional cooperation and innovation factors of 
TABLE 5: Result of the re-estimation of enterprise model.

\begin{tabular}{|c|c|c|c|}
\hline Variables & $\begin{array}{c}\text { Mode 3-1 } \\
\text { Poisson } \\
\text { panel (RE) }\end{array}$ & $\begin{array}{l}\text { Model 3-2 Poisson } \\
\text { panel (RE) }\end{array}$ & Model 3-3 Poisson panel (RE) \\
\hline Coefficients of the difference in the quality of university operations & $\begin{array}{c}26.647^{* * *} \\
(6.029)\end{array}$ & $\begin{array}{c}26.712^{* * *} \\
(5.899)\end{array}$ & $\begin{array}{c}23.661^{* * *} \\
(5.962)\end{array}$ \\
\hline $\begin{array}{l}\text { Squares of coefficients of the difference in the quality of university } \\
\text { operations }\end{array}$ & $\begin{array}{c}-17.786^{* * *} \\
(4.319)\end{array}$ & $\begin{array}{l}-17.559^{* * *} \\
(4.241)\end{array}$ & $\begin{array}{c}-14.872^{* * *} \\
(4.323)\end{array}$ \\
\hline $\begin{array}{l}\text { Proportion of enterprise development expenditure in total closing } \\
\text { assets }\end{array}$ & $\begin{array}{c}4.966^{* * *} \\
(0.511)\end{array}$ & $\begin{array}{l}4.970 \\
(0.510)\end{array}$ & $\begin{array}{l}4.981 \\
(0.511)\end{array}$ \\
\hline Proportion of the enterprise's personnel on R\&D positions & $\begin{array}{c}0.349^{* * *} \\
(0.028)\end{array}$ & $\begin{array}{c}0.351^{* * *} \\
(0.028)\end{array}$ & $\begin{array}{c}0.345^{* * *} \\
(0.028)\end{array}$ \\
\hline $\begin{array}{l}\text { Proportion of the graduates of " } 211 \text { Project" or " } 985 \text { Project" key } \\
\text { universities in senior executive positions of the enterprise }\end{array}$ & $\begin{array}{c}0.371^{* * *} \\
(0.055)\end{array}$ & $\begin{array}{c}0.369^{* * *} \\
(0.055)\end{array}$ & $\begin{array}{c}0.378^{* * *} \\
(0.055)\end{array}$ \\
\hline $\begin{array}{l}\text { Per-capita GDP of the province (provincial-level city or } \\
\text { autonomous region) }\end{array}$ & $\begin{array}{c}0.291^{* * *} \\
(0.006)\end{array}$ & $\begin{array}{c}0.290^{* * *} \\
(0.006)\end{array}$ & $\begin{array}{c}0.290^{* * *} \\
(0.006)\end{array}$ \\
\hline $\begin{array}{l}\text { Turnover of patents in the province (provincial-level city or } \\
\text { autonomous region where the enterprise is located) }\end{array}$ & $\begin{array}{c}-0.113^{* * *} \\
(0.032)\end{array}$ & $\begin{aligned}-0.116^{* * *} & (0.032)\end{aligned}$ & $\begin{array}{l}-0.128^{* * *} \\
(0.032)\end{array}$ \\
\hline Number of years since the enterprise became a listed one & $\begin{array}{l}-0.008 \\
(0.007)\end{array}$ & $\begin{array}{l}-0.007 \\
(0.007)\end{array}$ & $\begin{array}{l}-0.006 \\
(0.007)\end{array}$ \\
\hline Registered capital of the enterprise & $\begin{array}{c}-0.619^{* * *} \\
(0.176)\end{array}$ & $\begin{array}{c}-0.617^{* * *} \\
(0.176)\end{array}$ & $\begin{array}{c}-0.617^{* * *} \\
(0.177)\end{array}$ \\
\hline $\begin{array}{l}\text { Average score of the scores about the quality of university } \\
\text { operations }\end{array}$ & $\begin{array}{l}-0.038 \\
(0.111)\end{array}$ & $\begin{array}{l}-0.038 \\
(0.112)\end{array}$ & $\begin{array}{r}-0.037 \\
(0.111)\end{array}$ \\
\hline ( & & $\begin{array}{c}0.243 \\
(0.198)\end{array}$ & $\begin{array}{c}-0.154 \\
(0.248)\end{array}$ \\
\hline D12 & & & $\begin{array}{c}0.517^{* * *} \\
(0.185)\end{array}$ \\
\hline _Cons & $\begin{array}{c}-2.592^{* * *} \\
(0.971)\end{array}$ & $\begin{array}{c}-8.444^{* * *} \\
(2.070)\end{array}$ & $\begin{array}{c}-7.669^{* * *} \\
(2.074)\end{array}$ \\
\hline$N$ & 4598 & 4598 & 4598 \\
\hline Wald $\mathrm{chi}^{2}$ & 5193.43 & 5195.08 & 5207.09 \\
\hline Log likelihood & -27785.02 & -27784.23 & -27779.86 \\
\hline$P$ & 0.024 & $\leq 0.001$ & $\leq 0.001$ \\
\hline
\end{tabular}

Note. The values outside and inside the parentheses represent estimated coefficients and standard errors, respectively, while ${ }^{*},{ }^{* *}$, and ${ }^{* * *}$ represent significance levels of $1 \%, 5 \%$, and $10 \%$, respectively.

nationalities, the influence of the difference in educational level on enterprise innovation in the region is still significant.

Second, under the condition of other control variables that are given, the influence of the overall educational level of the universities in the province or city where the enterprise is located on the enterprise innovation is not significant. According to the results of models 3-1 to 3-3, the coefficient of Allsc is not significant, indicating that the influence of the overall educational level of universities in the province or city where listed enterprises are located on enterprise innovation is not significant. This result seems to be inconsistent with economic theory, but in fact it is easy to explain. The overall level of the quality of university operations in a region is highly positively correlated with the level of local economic development, so the inclusion of Agdp, D11, and other control variables leads to an insignificant Allsc coefficient.

Third, factors concerning knowledge spillover and crossprovincial cooperation have some influence on innovation, but the statistical significance is not high. The coefficient of dummy variable D11 is not significant, while the coefficient of D12 is significant at the level of $1 \%$. This indicates that knowledge spillover is related to spatial distance, and innovation cooperation in a remoter geographical distance is relatively weak.

(2) Robustness Test of Regional Model. Although there is little difference in significance between the models, further stability tests are necessary. Considering that omitted variables cause endogeneity problems, and that this model is compared with the enterprise model, the total score of the quality of university operations and dummy variables D11 and D12 are added as the indexes of controlling the overall regional educational level, the proportion of key universities, and the influence of geographical space, respectively, to conduct robustness tests. According to research findings (see Table 6), the "inverted U" hypothesis can still be proved. The coefficient of the quality difference among universities related to explanatory variables and the square of the coefficient are significant, and the coefficient of the quadratic term is negative. The value of the Gini Coefficient of the quality difference among universities in relation to the highest point of "inverted U" model is approximately 0.55 . Concurrently, the significance of the explanatory variable coefficient of the model for robustness test is a little higher than that of the 
TABLE 6: Robustness test for the model of regional data.

\begin{tabular}{|c|c|c|c|c|}
\hline & Model & $\begin{array}{c}\text { Model 6-9 Poisson } \\
\text { panel (RE) }\end{array}$ & $\begin{array}{c}\text { Model 6-10 Poisson } \\
\text { panel (RE) }\end{array}$ & Model 6-11 Poisson panel (RE) \\
\hline $\begin{array}{l}\text { Explanatory } \\
\text { variables }\end{array}$ & $\begin{array}{c}\text { Coefficients of the range of quality among } \\
\text { universities } \\
\text { Square of coefficients of the range of } \\
\text { quality among universities }\end{array}$ & $\begin{array}{l}8.867^{*} \\
(4.904) \\
-8.192^{*} \\
(4.503) \\
\end{array}$ & $\begin{array}{c}8.995^{*} \\
(4.903) \\
-8.449^{*} \\
(4.525) \\
\end{array}$ & $\begin{array}{c}10.182^{* *} \\
(4.926) \\
-9.309^{* *} \\
(4.514) \\
\end{array}$ \\
\hline \multirow{5}{*}{ Control variables } & $\begin{array}{c}\text { Per-capita internal expenditure for } \\
\text { science-and-technology activities } \\
\text { Number of full-time personnel on R\&D } \\
\text { positions } \\
\text { Average score of the scores of the quality } \\
\text { of university operations }\end{array}$ & $\begin{array}{c}1.836 \\
(9.306) \\
0.075^{* * *} \\
(0.008) \\
0.353 \\
(0.407)\end{array}$ & $\begin{array}{c}1.711 \\
(9.612) \\
0.074^{* * *} \\
(0.008) \\
0.404 \\
(0.409)\end{array}$ & $\begin{array}{c}1.508 \\
(9.706) \\
0.073^{* * *} \\
(0.007) \\
0.341 \\
(0.393)\end{array}$ \\
\hline & Per-capita GDP & & $\begin{array}{c}9.738^{* *} \\
(4.911)\end{array}$ & $\begin{array}{l}7.471^{* *} \\
(3.987)\end{array}$ \\
\hline & Indexes of marketization degree & & $\begin{array}{c}1.401 \\
(1.616)\end{array}$ & $\begin{array}{c}1.321 \\
(1.601)\end{array}$ \\
\hline & D12 & & & $\begin{array}{r}-0.362 \\
(0.676) \\
-0.901^{*} \\
(0.542)\end{array}$ \\
\hline & Constant terms & $\begin{array}{l}-1.161 \\
(1.462)\end{array}$ & $\begin{array}{l}-1.581 \\
(1.632)\end{array}$ & $\begin{array}{l}-1.728 \\
(1.630)\end{array}$ \\
\hline Model & $\begin{array}{c}N \\
\text { Wald chi } \\
\text { Log likelihood } \\
p\end{array}$ & $\begin{array}{c}186 \\
140.340 \\
-409.510 \\
\leq 0.001\end{array}$ & $\begin{array}{c}186 \\
140.805 \\
-409.650 \\
\leq 0.001 \\
\end{array}$ & $\begin{array}{c}186 \\
157.821 \\
-435.593 \\
\leq 0.001 \\
\end{array}$ \\
\hline
\end{tabular}

Note. The values outside and inside the parentheses represent estimated coefficients and standard errors, respectively, while ${ }^{*},{ }^{* *}$ and ${ }^{* * *}$ represent significance levels of $1 \%, 5 \%$ and $10 \%$, respectively.

initial model, which further proves the correctness of the hypothesis. In addition, similar to the enterprise model, under the condition of other given control variables, factors of knowledge spillover and cross-provincial cooperation have a certain influence on innovation, indicating that knowledge spillover is related to spatial distance.

\section{Conclusions and Suggestions}

The imbalance of educational resources will affect innovation, which is similar to previous studies [32]. This article takes a further step to find the boundary value of this imbalance. From the micro and macro perspectives, this article studies the influence of the range of quality among universities on the differentiation of enterprises and countries (regions) through the establishment of enterprise and regional innovation counting panel models. It has been found that under the current quality of university operations evaluation system, the range of quality among universities and innovation output level show the feature of "an inverted U." In other words, a too large or too small range of quality among universities will weaken the positive influence on innovation, which is similar to the research results of Lai Desheng et al. from 2015. However, it is worth noting that the research in this article finds that the coefficient of the quality difference among universities, which corresponds to the optimal innovation output of enterprises, is higher than that of the regional innovation output. Enterprises and countries (regions) have different sensitivities to the signals released by universities, and the traits of the differences in the quality of higher education have different influences on the innovation level of enterprises and countries (regions). On the premise that the overall level of the quality of university operations is unchangeable, compared with countries and regions, the great range of quality among universities is more favorable to enterprise innovation.

This article has certain limitations. In recent years, China has proposed the "double carbon" goal, that is, to reach the carbon peak in 2030 and to achieve carbon neutralization in 2060. In addition to the variables mentioned in this article, there should be environmental protection policies and data availability restrictions. This article does not use this variable as a control variable to verify the robustness of the model. In the future, policy influence can be added to deepen the research in this article. Based on the above research, the specific conclusions and suggestions are as follows:

First, it is an objective fact that the range of quality among universities has a significantly different influence on the innovation of enterprises and countries (regions). In the scenario that other conditions are equal, if the Gini Coefficient of the comprehensive score in terms of the quality of university operations published by http://www.cuaa.net/ is used to 
measure the range of quality among universities, it is reasonable that the value suitable for national (regional) innovation should be approximately 0.55 , but for enterprise innovation it is reasonable that the value should be approximately 0.75 . It is not scientific to simply determine whether the development goal of a university is basic research or applied research. It is the key to solve the problem to provide different and applicable signals of higher education for enterprises and countries (regions). This is the work to be done by the third-party organizations, and the development of a university should follow its internal law of education. Universities cannot follow the principle of maximizing enterprise profits, nor can they be the tool of the government in pursuit of political achievements. Universities should pursue quality improvement and shoulder the important task of the progress of social civilization and national scientific and technological innovation. To a certain extent, the difference in the path of the influence of the difference in the quality of university operations on the innovation of enterprises and a country explains why the country has cultivated a large number of talents, but the lack of the talents who can break through "bottleneck" technologies still exists. The so-called "bottleneck" technologies are often the technologies that "have escaped from the net" and have little to do with the profits of enterprises in a certain period. The cultivation of relevant talents is the national (regional) educational goal, which is inconsistent with the enterprise goal. Therefore, what should be done in the future is not to force universities to adapt themselves to a rapidly changing market, but to establish better evaluation systems by third-party institutions so that companies and the government can more clearly judge the traits of the talents and scientific research achievements from universities.

Second, there are significant differences in quality between universities in different regions. Those differences to an extent reflect the irrationality of university resource allocation. Given the fact that most universities are run by the government in China, the difference in quality between different universities in different regions, to a great extent, depends on the government's biased input, so it is of practical significance to consider the difference in resource input through the range of quality among universities. Shanghai, Beijing, Jiangsu, and other provincial-level administrative regions are characterized by a moderate range of quality among universities. In addition to not increasing the number of "985 Project" and "211 Project" key universities, it is not suitable to continue to increase the biased allocation of higher education resources targeted at "demonstration universities" or the key universities with other names. The excessively high range of quality among universities in provinces such as Anhui, Sichuan, Zhejiang, and Fujian has restrained local innovation to a certain extent. Therefore, more support should be given to nonkey universities in these regions. Universities in provinces like Qinghai and Guangxi are characterized by the situation of "general backwardness with little difference," which needs to be greatly improved by the country (region).

Third, university alliances and the inter-regional development of universities are conducive to the flow of knowledge and the cultivation of innovative talents, thus promoting enterprise innovation. It is necessary to establish university alliances based on geography and administrative divisions so that enterprise and regional innovation demands can be met through information transmission between universities. Knowledge spillover is related to spatial distance, and innovation cooperation in a remote geographical location is relatively weak. There are few highquality universities in provinces such as Hebei, Shanxi, and Hainan, which have no "985 Project" key universities. However, these provinces also have some strength with regard to innovation, which is even higher than Anhui and Gansu, which have "985 Project" key universities. These provinces still can obtain certain innovation ability by attracting the universities from the surrounding developed areas to set up branch campuses by virtue of their advantage in geographical location or enjoying the benefits of talent flow from the neighboring provinces and cities by virtue of their advantages in natural resource endowment and economic development. For example, more than 20 institutions of higher learning from Beijing and northeast China have set up branch campuses in Langfang, Hebei Province. Shanxi and Hainan have issued the "Hundred Experts Program" and the Interim Measures for Attracting High-level Professional and Technical Personnel, respectively, to introduce high-quality human capital, including fresh graduates with impressive educational backgrounds. This shows from another perspective that although the inhibiting effect of excessive range of quality among universities in the region on innovation can be alleviated by other means, such alleviation may require the region to have regional comparative advantage or to introduce talents by increasing administrative costs.

\section{Data Availability}

The data that support the findings of this study are available from the corresponding author upon reasonable request.

\section{Conflicts of Interest}

The authors declare that they have no conflicts of interest.

\section{Acknowledgments}

This study was supported by Industry Education Collaborative Education Project of Higher Education Department of Education Ministry, 2018, "Innovation and Entrepreneurship Incubation Platform for College Students Based on Cloud Computing” (201801079062).

\section{References}

[1] WIPO, "Global innovation index," Internet Economy, 2018.

[2] T. Zhuang and H. Wu, "Measurement research on official industry-university-research triple helix in our country based on patent data-also on the role played by the government in industry-university-research cooperation," Management World, vol. 28, no. 8, pp. 175-176, 2013. 
[3] M. Gu, "On the similarities and differences between the western universities and China universities," Journal of Higher Education, vol. 38, no. 3, pp. 1-3, 2017.

[4] J. A. Schumpeter, Theory of Economic development, Routledge, 2017.

[5] C. Freeman and Y. Zhang, "[UK] compiled by christophe freeman and translated by zhang yuxuan," Technology Policy and Economic Performance: Lessons from Japan, Southeast University Press, Nanjing, 2008.

[6] P. Cooke, M. G. Uranga, and G. Etxebarria, "Regional innovation systems: i," Research Policy, vol. 26, no. 4-5, pp. 475-491, 1997.

[7] M. R. Della Peruta, M. Del Giudice, R. Lombardi, and P. SotoAcosta, "Open innovation, product development, and intercompany relationships within regional knowledge clusters," Journal of the Knowledge Economy, vol. 9, no. 2, pp. 680-693, 2018.

[8] H. Tian, T. Zeng, X. Wang et al., "On advancing the system of talent cultivation in priority areas of manufacturing in China," Educational Research, vol. 432, no. 1, pp. 4-16, 2016.

[9] W. B. MacLeod, E. Riehl, J. E. Saavedra, and M. Urquiola, "The big sort: college reputation and labor market outcomes," American Economic Journal: Applied Economics, vol. 9, no. 3, pp. 223-261, 2017.

[10] M. Spence, "Job market signaling," Quarterly Journal of Economics, vol. 87, no. 3, pp. 355-374, 1973.

[11] H. Wu, W. Zeng, L. Zhou, Y. Yang, G. Zhang, and Y. Cai, "Strategic transition from academic organization to innovative organization ---Interpretation on education-S\&T-Economy integration," $R$ \& $D$ Management, vol. 20, no. 3, pp. 118-121, 2008.

[12] L. Li and X. Xue, "Establishing the classification system of higher education on the basis of talent cultivation," Educational Research, vol. 458, no. 3, pp. 62-69, 2018.

[13] J. Zhang, "Innovate in classified evaluation management system to facilitate the differentiation development of higher learning institutions," China Higher Education, 2018.

[14] R. Aamoucke, "Fields of knowledge, types of higher education institutions, and innovative start-ups," Innovative Start-Ups and the Distribution of Human Capital, Springer International Publishing, Berlin, 2016.

[15] G. S. Becker and H. Guo, Human Capital: A Theoretical and Empirical Analysis with Special Reference to Education, China CITIC Press, Beijing, 2007.

[16] M. D. Santoro and A. K. Chakrabarti, "Firm size and technology centrality in industry-university interactions," Research Policy, vol. 31, no. 7, pp. 1163-1180, 2002.

[17] Y. B. Chang and V. Gurbaxani, "Information technology outsourcing, knowledge transfer, and firm productivity: an empirical analysis," Management Information Systems Quarterly, vol. 36, no. 4, pp. 27-54, 2012.

[18] R. Andersson, J. M. Quigley, and M. Wilhelmsson, "Urbanization, productivity, and innovation: evidence from investment in higher education," Journal of Urban Economics, vol. 66, no. 1, pp. 2-15, 2009.

[19] L. Zhao, J. Shi, P. Wang, W. Wang, and T. Xu, "A study on the institutional type and regional difference of higher education quality---with an analysis of higher education resource distribution and quality structure in China," Tsinghua Journal of Education, vol. 34, no. 5, pp. 1-12, 2013.

[20] D. Lai, Q. Wang, and D. Shi, "On differences of higher educational quality and regional innovation," Educational Research, vol. 37, no. 2, pp. 41-50, 2015.
[21] F. G. Brasil, I. H. de Mattos e Silva, and A. V. Zambello, "The effects of policy change on Brazil's public higher education system," Latin American Policy, vol. 8, no. 2, pp. 313-331, 2017.

[22] A. Triguero and S. Fernández, "Determining the effects of open innovation: the role of knowledge and geographical spillovers," Regional Studies, vol. 52, no. 5, pp. 632-644, 2018.

[23] J. Owen-Smith, M. Riccaboni, F. Pammolli, and W. W. Powell, "A comparison of U.S. And European university-industry relations in the life sciences," Management Science, vol. 48, no. 1, pp. 24-43, 2002.

[24] D. B. Audretsch and M. P. Feldman, "R\&D spillovers and the geography of innovation and production," The American Economic Review, vol. 86, no. 3, pp. 630-640, 1996.

[25] E. Xue, "Policy analysis on collaborative innovation and cultivation of innovative talents in universities," China Higher Education Research, vol. 28, no. 12, pp. 26-31, 2012.

[26] M. Pan and R. Che, "On the positioning of application-oriented universities," Journal of Higher Education, vol. 30, no. 5, pp. 35-38, 2009.

[27] W. Min, "Research on Chinese higher education development strategies for 2035 from economic perspective," Education \& Economy, vol. 34, no. 2, pp. 3-42, 2018.

[28] X. Liu, T. Gao, and J. Zhou, Report on regional innovation capacity in China, Science Press, Beijing, 2013.

[29] R. Moreno, R. Paci, and S. Usai, "Geographical and sectoral clusters of innovation in Europe," The Annals of Regional Science, vol. 39, no. 4, pp. 715-739, 2005.

[30] G. Fan, X. Wang, and H. Zhu, NERI INDEX of marketization of China's provinces 2011 report, Economic Science Press, Beijing, 2011.

[31] J. Hartog, Y. Sun, and X. Ding, "University rank and bachelor's labour market positions in China," Economics of Education Review, vol. 29, no. 6, pp. 971-979, 2010.

[32] M. Dollinger, J. Lodge, and H. Coates, "Co-creation in higher education: towards a conceptual model," Journal of Marketing for Higher Education, vol. 28, no. 2, pp. 210-231, 2018. 